\title{
Valve interstitial cells induce donor-specific T-cell anergy
}

Puspa Batten, PhD

Ann M. McCormack, BSc

Marlene L. Rose, PhD

Magdi H. Yacoub, FRS

See related editorial on page 8 .

From the Division of Cardiothoracic Surgery, National Heart and Lung Institute, Imperial College of Technology, Science and Medicine at Harefield Hospital, Harefield, Middlesex, United Kingdom.

Received for publication Sept 19, 2000; revisions requested Jan 18, 2001; revision received Jan 26, 2001; accepted for publication Feb 5, 2001

Address for reprints: Puspa Batten, PhD, Division of Cardiothoracic Surgery, National Heart and Lung Institute, Imperial College of Technology, Science and Medicine at Harefield Hospital, Heart Science Centre, Harefield, Middlesex UB9 6JH, United Kingdom (E-mail: puspa.batten@ harefield.nthames.nhs.uk).

J Thorac Cardiovasc Surg 2001;122:129-35

Copyright (C) 2001 by The American Association for Thoracic Surgery

$0022-5223 / 2001 \$ 35.00+0 \quad \mathbf{1 2 / 1 / 1 1 4 9 4 0}$

doi:10.1067/mtc.2001.114940

Results: Valve endothelial and interstitial cells express similar levels of human leukocyte antigens and adhesion and costimulatory molecules, which are either induced or upregulated after interferon $\gamma$ treatment. T-cell responses to endothelial cells were detected after interferon $\gamma$ treatment, but responses to interferon $\gamma$-treated interstitial cells were not detected. This lack of response resulted in the induction of T-cell anergy, which was reversed by the presence of the costimulatory molecule B7-1.

Conclusions: Although valve endothelial and interstitial cells express a similar range of cell-surface molecules, it is only the endothelial cells that are immunogenic. In addition, we have shown that these 2 cell types interact in a donorspecific manner to orchestrate the immune response and therefore may have clinical relevance in the allogeneic response of the heart valve recipients.

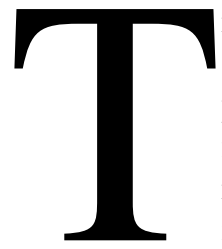

ransplantation of human cardiac valve homografts is successful with good long-term results in the absence of immunosuppressive therapy. ${ }^{1,2}$ Blood group or HLA antigens between donor and recipient are not matched because it is thought that antigenicity is minimal as a result of the lack of blood vessels in the cardiac valves. Nevertheless, it is highly possible that homografts can be damaged as shown by donor-specific immune responses, which lead to immunologic damage by both humoral and cellular factors. ${ }^{3-6}$ This has been shown to be particularly evident in children who receive valvular allografts. ${ }^{7-9}$

Although evidence that human valve allografts are immunogenic is limited, the underlying cellular mechanisms involved are still unclear. Endothelial cells, normally the barrier between blood and tissue, have long been implicated in provoking immune responses between the allograft and the recipient's immune cells, leading to rejection. ${ }^{10-12}$ This has been demonstrated in vitro by using endothelial cells cultured from valve leaflets that are capable of eliciting T-cell responses. ${ }^{13,14}$ This would then suggest that valve allografts that are lined with endothelium would be rejected. Low doses of antibiotics used to preserve the valves may lower the immunogenicity of the 


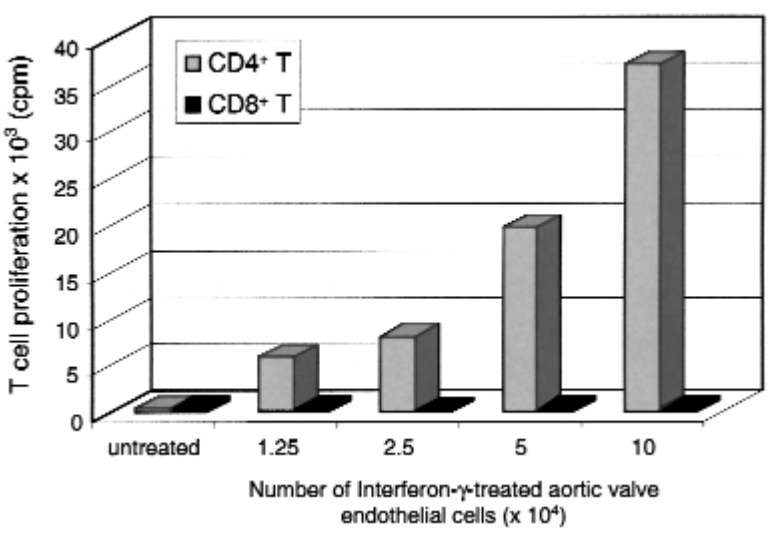

Figure 1. Purified human CD4 ${ }^{+} \mathrm{T}$ cells but not $\mathrm{CD8}^{+} \mathrm{T}$ cells proliferate to valve endothelial cells. Data are expressed as mean counts per minute \pm SD of triplicate wells for T-cell proliferation.

valves. ${ }^{15}$ However, the interplay between the endothelium and other cells, such as the interstitial cells, that make up the valves may provide an insight into the cellular mechanisms involved in rejection. In this study we have used highly purified human $\mathrm{T}$ cells to investigate the relative immunogenicity of both the human valve endothelial and interstitial cells mismatched at the DR locus.

\section{Materials and Methods \\ Isolation and Culture of Cells}

Interstitial and endothelial cells were isolated from either valve leaflets or donor aorta by means of differential enzymatic digestion, as previously described, ${ }^{15,16}$ and cultured in tissue culture-grade flasks. Skin and pericardial fibroblasts were isolated as previously described ${ }^{16}$ from either the human forearm from a group of normal control subjects, from a genetic screening program, or from a trimmed piece of pericardium from transplant recipients, respectively.

The purity of the endothelial and interstitial cells was determined by means of flow cytometry after staining with monoclonal antibodies (mAbs) against either endothelial cells (EN4, Monosan; TCS Biologicals, Buckingham, United Kingdom) or fibroblasts (antifibroblast antibody; Dianova, Hamburg, Germany). Differential collagenase treatment usually yielded a purity of 50\% to $95 \%$ endothelial cells and $10 \%$ to $90 \%$ fibroblasts. Ulex-coated Dynabeads (Dynal, Bromborough, United Kingdom), which specifically bind endothelial cells, were used as specified by manufacturer's instructions to improve purity to greater than $95 \%$ endothelial cells. This method yielded greater than $95 \%$ endothelial cells. Endothelial cells were used between passages 6 and 9 and were used for experiments if their purity was greater than $95 \%$. Interstitial cells were used between passages 6 and 9 , and their purity was confirmed before each experiment by means of the anti-fibroblast antibody. Interstitial cells were only used if purity was greater than $95 \%$. The phenotype of the interstitial cells has been shown not to change up to passage 10 with regard to fibroblast surface antigen and smooth muscle $\alpha$-actin. ${ }^{16}$ The phenotype of valve endothelial cells also did not change with regard to EN4 (personal communication, Dr Patricia Taylor, National Heart and Lung Institute, Imperial College, United Kingdom). The pheno-

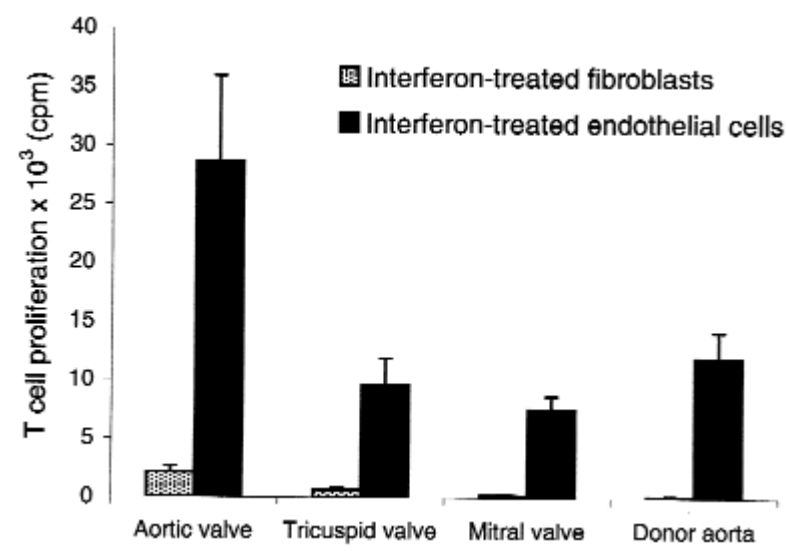

Figure 2. Valve interstitial cells do not elicit CD4+ T-cell proliferation. Data are expressed as mean counts per minute \pm SD of triplicate wells for T-cell proliferation.

types of both valve endothelial and interstitial cells were found to be relatively consistent.

For experiments, both endothelial and interstitial cells were used either untreated or treated with recombinant human interferon $\gamma$ (IFN- $\gamma ; 500 \mathrm{U} / \mathrm{mL}$ for 4 days). Endothelial cells were cultured from aortic valves, mitral valves, tricuspid valves, and veins of umbilical cords (isolation is described elsewhere ${ }^{17}$ ), whereas interstitial cells were cultured from aortic valves, mitral valves, tricuspid valves, pericardium, and skin. Tissue was obtained from heart transplant recipients with no previous history of heart valve disease after ethical approval. Pericardial tissue was dissected at the time of transplantation from recipient hearts.

\section{Cell Lines}

DAP.B $7^{18}$ is a major histocompatibility complex (MHC) class II-negative mouse L-cell fibroblast transfectant cell line expressing surface human B7-1 (CD80) molecules (a gift from Professor R. I. Lechler, Imperial College, London, United Kingdom).

\section{Monoclonal Antibodies and Flow Microfluorimetric Analysis}

Anti-HLA class I mAb (W6/32), anti-HLA class II mAb (L243, $\mathrm{DR} \alpha$ ), and anti-intercellular adhesion molecule 1 (CD54 or ICAM-1) were used at saturating concentrations (ATCC, Rockville, Md). Anti-lymphocyte function-associated antigen 3 (CD58 or LFA-3; Serotec, Oxford, United Kingdom) and antiCD40 (Serotec) were used at $10 \mu \mathrm{g} / \mathrm{mL}$. Mouse chimeric protein, cytotoxic T-cell activation antigen 4 human immunoglobulin $\gamma$ heavy chain (a kind gift of Peter Lane, Basel Institute of Immunology, Switzerland), was used to stain the family of costimulatory molecules termed B7 at saturating concentration.

Surface antigen expression on interstitial and endothelial cells was measured with indirect immunofluorescence and flow microfluorimetric analysis, as previously described. ${ }^{19}$ Secondary antibodies used were either fluorescein isothiocyanate-conjugated rabbit anti-mouse immunoglobulin (Dako Ltd) or fluorescein isothiocyanate-conjugated sheep anti-human immunoglobulin G ( $\gamma$ chain; Binding Site, Birmingham, United Kingdom). Cells were 

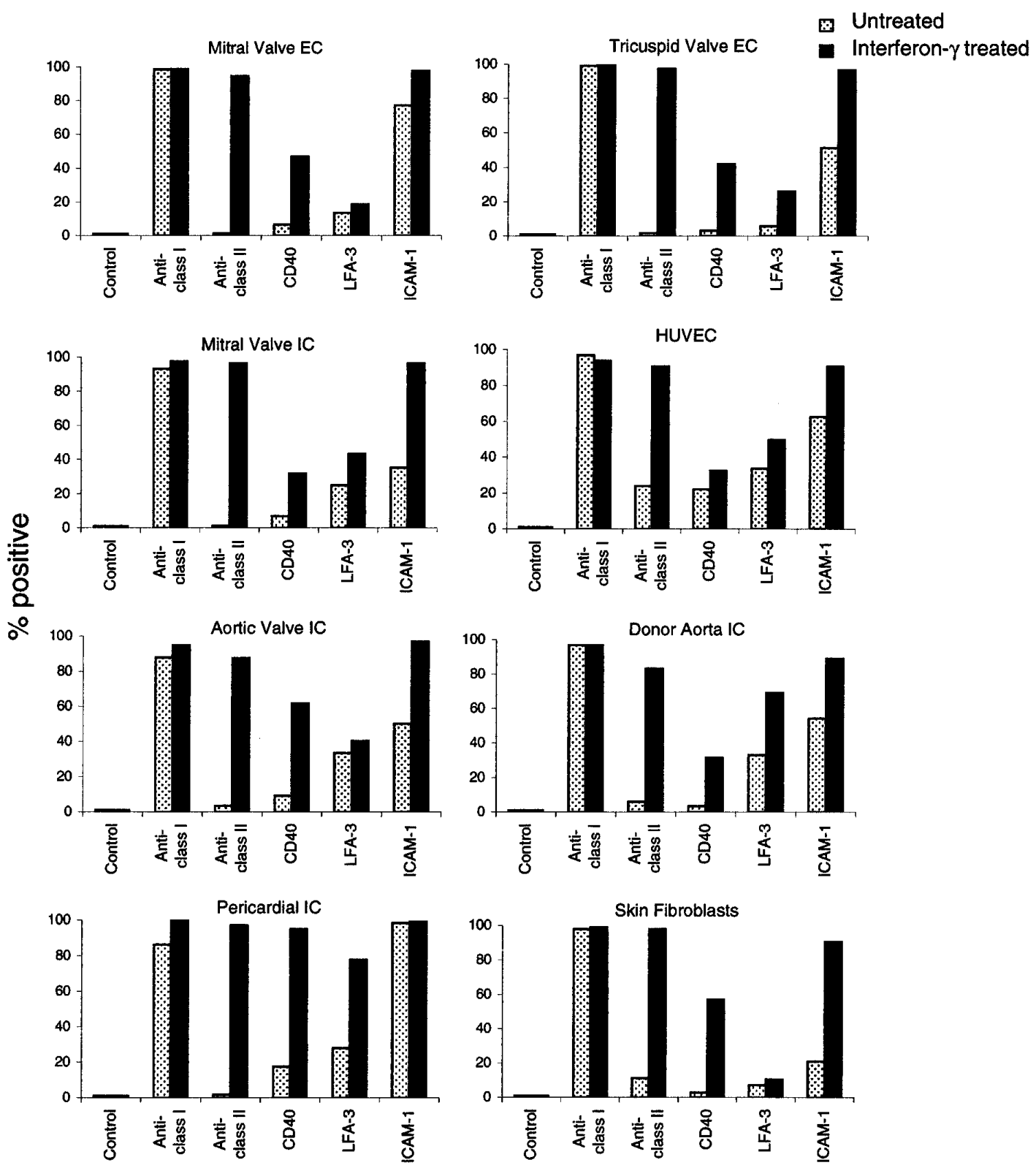

\section{Monoclonal Antibodies}

Figure 3. Phenotypic characterization of endothelial and interstitial cells cultured from valve and nonvalve tissue. Expression of cell-surface antigens before and after IFN- $\gamma$ treatment was carried out with appropriate mAbs against HLA class I, HLA class II, CD40, lymphocyte function-associated antigen 3 (LFA-3), and intercellular adhesion molecule 1 (ICAM-1), as described in the "Materials and Methods" section. The negative controls were fluorescein isothiocyanate-conjugated anti-mouse secondary antibodies only. Data are expressed as percentages of positive staining.

analyzed on an EPICS XL-MCL Flow Cytometer (Beckman Coulter, High Wycombe, United Kingdom).

\section{Purification of Human CD4 ${ }^{+}$and $\mathrm{CD8}^{+} \mathrm{T}$ Cells}

This method has been described in detail elsewhere. ${ }^{20} \mathrm{CD} 4^{+}$and $\mathrm{CD}^{+} \mathrm{T}$ cells were purified from peripheral blood mononuclear cells collected from normal individuals by means of a 2-step neg- ative selection method. First, adherent cells were depleted by incubation on tissue-culture grade petri dishes for 1 hour at $37^{\circ} \mathrm{C}$. Nonadherent cells were then eluted and washed. Second, magnetic immunoselection with a MidiMACS column (LS+) and a CD4 ${ }^{+}$ or $\mathrm{CD}^{+}$T-cell isolation kit was used, as specified by manufacturer's instructions (Miltenyi Biotec, Surrey, United Kingdom). Flow microfluorimetric analysis indicated that more than $99 \%$ of the 
A

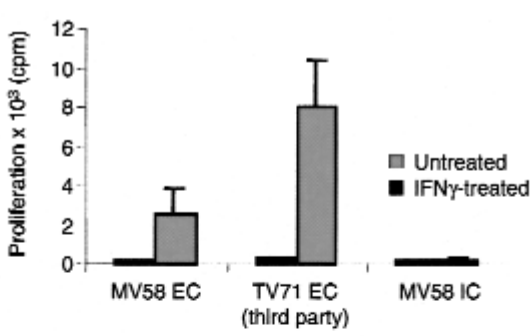

Figure 4. Valve interstitial cells induce a state of T-cell nonresponsiveness. A, CD4 ${ }^{+} \mathrm{T}$ cells respond to both IFN- $\gamma$-treated mitral valve endothelial cells 58 (MV58 EC) and to third-party tricuspid valve endothelial cells (TV71 EC) for 6 days. B, The 2-step tolerance-induction protocol described in the "Materials and Methods" section was used. Data are expressed as mean counts per minute \pm SD of triplicate wells.

resulting cells stained positively for CD4 or CD8 and CD3, and less than $2 \%$ were stained with the other non-T-cell antibodies. The purity of the $\mathrm{CD}^{+}$or $\mathrm{CD} 8^{+} \mathrm{T}$ cells was further established by nonresponsiveness to phytohemagglutinin stimulation.

\section{T-Cell Proliferation Assays}

Purified T cells $\left(10^{5}\right)$ were cocultured with stimulator cells $(2.5 \times$ $10^{4}$ untreated or IFN- $\gamma$-treated endothelial or interstitial cells) for 6 days in a humidified carbon dioxide incubator at $37^{\circ} \mathrm{C}$. In some experiments DAP.B7 $\left(2.5 \times 10^{4}\right)$ was also added with the interstitial cells at the time of seeding. Proliferation of responder T cells was determined by the addition of tritiated thymidine $(1 \mu \mathrm{Ci} /$ well, Amersham Corp, Arlington Heights, Ill) for the last 18 hours of culture. The samples were harvested onto glass fiber filters, and tritiated thymidine incorporation was determined with a Wallac 1450 Microbeta Trilux $\beta$-counter (Wallac, EG\&G, Milton Keynes, United Kingdom). Results are expressed as mean counts per minute for triplicate samples \pm SD. All experiments were performed on at least 5 different occasions, and representative results are shown in each case.

\section{Two-Step Anergy Induction}

Purified CD4 ${ }^{+} \mathrm{T}$ cells $\left(3 \times 10^{6}\right.$ cells per well in a 6 -well plate $)$ were cocultured with either recombinant human IFN- $\gamma$-treated (500 $\mathrm{U} / \mathrm{mL}$ for 4 days $)$ or untreated interstitial cells $\left(7.5 \times 10^{5}\right.$ cells per well in a 6-well plate) for 24 hours. In some experiments mAbs were also added. Controls also included T cells alone. T cells were then removed from the interstitial cells and challenged $\left(10^{5}\right)$ with either $2.5 \times 10^{4}$ IFN- $\gamma$-treated valve endothelial cells from the same donor or with complete DR-mismatched third-party valve endothelial cells. After 6 days, T-cell proliferation was determined, as described previously. All experiments were performed on at least 5 different occasions, and representative results are shown in each case.

\section{Results}

It has been previously shown that both macrovascular and microvascular endothelial cells are capable of activating and inducing T-cell proliferation in human and mouse in vitro models. ${ }^{21,22}$ A typical example from 6 independent experiments showed that only purified $\mathrm{CD}^{+}$and not $\mathrm{CD}^{+} \mathrm{T}$ cells responded to IFN- $\gamma$-treated aortic valve endothelial cells mismatched at both DR loci in a dose-dependent manner (Figure 1). Similar results were obtained with endothelial cells isolated from other valve tissue, such as tricuspid and mitral valves.

However, when interstitial cells cultured from the same valves as the endothelial cells were cocultured with purified $\mathrm{CD}^{+} \mathrm{T}$ cells, there was either little or no response. This was evident with cells from aortic, tricuspid, and mitral valves, as well as from donor aorta (Figure 2). Therefore, endothelial and interstitial cells from various valve and nonvalve tissues were characterized for possible differences in their cell-surface expression of various costimulatory, adhesion, and MHC molecules before and after treatment with IFN- $\gamma$ to investigate why valve interstitial cells are such poor T-cell stimulators. We used skin fibroblasts and human umbilical vein endothelial cells as controls for comparing valve interstitial and endothelial cells, respectively.

As shown in Figure 3, constitutive expression of $\mathrm{MHC}$ class I was upregulated after IFN- $\gamma$ treatment (the mean fluorescence intensity, an arbitrary unit for levels of cellsurface molecules per cell, was generally increased by a factor of 8 to 10 times; data not shown). MHC class II expression was induced or increased from $0 \%$ to $5 \%$ to a maximum of $100 \%$ positive in all the cells tested, indicating that both endothelial cells and interstitial cells from the valve are capable of cognate interactions with the T-cell receptor. The costimulatory adhesion molecules CD40, lymphocyte function-associated antigen 3 , and intercellular adhesion molecule 1 were all upregulated after IFN- $\gamma$ treatment both in the valve endothelial and interstitial cells, albeit not all to the same extent. This may be due to interisolate variations. Nevertheless, it is clear that both valve endothelial and interstitial cells do not differ greatly in their expression of costimulatory and adhesion molecules. We did, however, fail to find expression of the family of costimulatory molecules called B7 (CD80/CD86) in all the cells tested before or after IFN- $\gamma$ treatment (data not shown). 
Experiments with a 2-step tolerance induction method were used to further investigate the lack of T-cell response to valve interstitial cells. By using valve interstitial and endothelial cells from the same valve tissue (MV58), we confirmed that only IFN- $\gamma$-treated endothelial cells and not interstitial cells elicited a primary T-cell alloresponse (Figure 4, A). Similarly, a strong primary T-cell alloresponse was elicited to the third-party valve endothelial cell control (TV71). The differences in the magnitude of the primary responses between MV58 and TV71 endothelial cells can be attributed to interisolate variations, particularly because the endothelial cell populations were mismatched at both DR loci with the responding $\mathrm{T}$ cells. However, if the $\mathrm{T}$ cells were cocultured with the interstitial cells first and then rechallenged with endothelial cells from the same valve tissue, the T cells completely failed to respond (Figure 4, B). A state of MHCspecific T-cell nonresponsiveness or anergy was induced, whereas T-cell responses to third-party endothelial cells were still intact. Indeed, if $\mathrm{T}$ cells were cocultured with either untreated MV58 interstitial cells (no MHC class II expression) or just on plastic before rechallenge, secondary T-cell responses to both MV58 and TV71 valve endothelial cells were equivalent to those seen in the primary T-cell responses (Figure 4, A). To further confirm that T-cell anergy was MHC class II restricted, the addition of anti-MHC class II $\mathrm{mAb}$ L243 during the primary coculture step completely abolished the induction of T-cell nonresponsiveness to MV58 endothelial cells. However, it was interesting to find that the addition of anti-CD40 mAb did not reverse T-cell energy.

Full T-cell activation requires 2 signaling events. The first is an antigen-specific signal delivered by the MHCantigen complex interacting with the T-cell receptor, and the crucial second signal has been defined as costimulation..$^{23,24}$ To confirm that the lack of T-cell responsiveness to valve interstitial cells is due to either partial or absent second signals, transcostimulation provided by human B7-1 presented on a bystander cell (DAP.B7) rescued the absent T-cell responses to IFN- $\gamma$-treated valve interstitial cells (TV84 IC) with more than comparable T-cell stimulation, as seen against the IFN- $\gamma$-treated valve endothelial cells (TV84 EC) from the same valve tissue (Figure 5). However, there was no response to DAP.B7 alone, indicating that DAP.B7 itself is not capable of stimulating $\mathrm{CD}^{+} \mathrm{T}$ cells alone.

\section{Discussion}

Previous clinical and experimental studies have indicated that cardiac valve tissue is immunogenic, as shown by the presence of anti-donor HLA antibodies in patients after aortic valve replacement ${ }^{3,4,9}$ and by $\mathrm{T}$-cell alloresponses to endothelial cells isolated from fresh and cryopreserved valves in vitro. ${ }^{14,25,26}$ In the present study the latter findings have been confirmed, where endothelial cells from various valve tissues were found to stimulate $\mathrm{CD}^{+} \mathrm{T}$ cells.

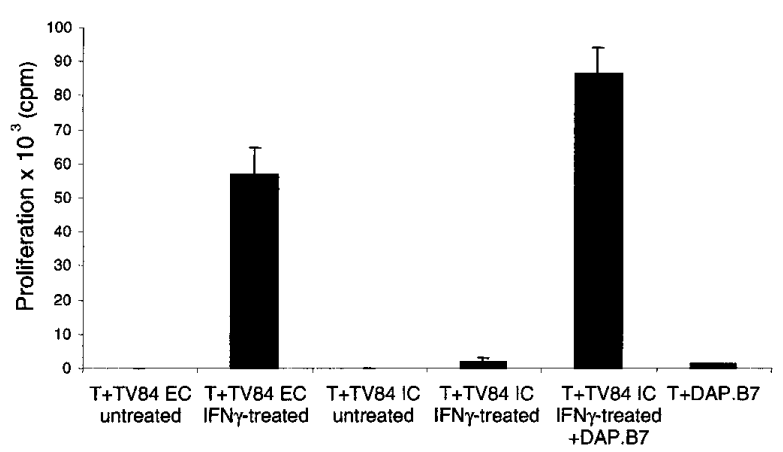

Figure 5. T-cell responses to valve interstitial cells are rescued by B7-1 transcostimulation. CD4 ${ }^{+} \mathrm{T}$ cells $\left(10^{5}\right)$ were cocultured with $2.5 \times 10^{4}$ untreated or IFN- $\gamma$-treated TV84 endothelial cells (EC) or interstitial cells (IC). The transfectant, DAP.B7, which expresses human B7-1, was also added to either T-cell responses to IFN$\gamma$-treated TV84 interstitial cells or to $T$ cells alone. Data are expressed as mean counts per minute \pm SD of triplicate wells.

However, interstitial cells cultured from the same valve leaflets were found to be relatively nonimmunogenic.

Phenotypically, the valve interstitial cells were very similar to the valve endothelial cells when the expression of various adhesion, costimulatory, and HLA molecules was compared before and after treatment with IFN- $\gamma$. Yet only the valve endothelial cells were capable of stimulating $\mathrm{T}$ cells in a B7-independent manner. Immunohistochemical staining of valve leaflets has shown that the layer of endothelial cells covering the surface is constitutively HLA class II positive, and like most other human endothelial cells isolated from tissue, subsequent culture in vitro sees the loss of constitutive HLA class II expression until stimulated with IFN- $\gamma$. Unlike the endothelial cells, valve interstitial cells are HLA class II negative within the native valve leaflet and remain HLA class II negative in in vitro culture until stimulated with IFN$\gamma$ (personal communication, Dr Patricia Taylor, National Heart and Lung Institute, Imperial College, United Kingdom). Human endothelial cells have been described to be devoid of the presence of both the transcript and protein for the family of B7 molecules. ${ }^{27,28}$ Valve endothelial cells, as well as interstitial cells, also show absence of B7 molecule expression. However, whether the cells display B7 in the native valve leaflet still remains to be elucidated.

However, when primary $\mathrm{CD}^{+} \mathrm{T}$ cells are cocultured with HLA class II-expressing valve interstitial cells, the T cells become refractory to further stimulation by valve endothelial cells expressing the same HLA antigens. The indication that the $\mathrm{T}$ cells were still viable and that the nonresponsiveness was DR restricted was shown by intact responses to both exogenous IL-2 (data not shown) and third-party DRmismatched endothelial cells, respectively. This suggested that signal 1 (cognate interaction between the T-cell receptor and the MHC molecule) in T-cell activation was occurring in 
the absence of signal 2 (costimulation), leading to T-cell nonresponsiveness. It was therefore reassuring to find that the addition of the costimulatory molecule B7-1 presented on a bystander cell (DAP.B7) restored full T-cell activation against the valve interstitial cells. The finding that valve interstitial cells (or valve fibroblasts) expressing similar levels of adhesion and HLA class II molecules to endothelial cells lack the ability to initiate allostimulation is not unique. Other reports have shown that parenchymal cells, such as human dermal fibroblasts and epithelial cells, are also unable to stimulate $\mathrm{T}$ cells in a similar fashion. ${ }^{29,30}$ It appears that these nonprofessional antigen-presenting cells are deficient in as-yet undefined costimulatory factors, which appear to be present on endothelial cells. As a consequence of this costimulatory deficiency, we have shown that valve interstitial cells can induce T-cell anergy. Whether these effects take place in vivo is difficult to ascertain, but the cellular state of the valve before implantation may be of crucial importance. For instance, it may be beneficial to remove the endothelial cell layer from the valve either manually or by means of high-dose antibiotic treatment, thus exposing the interstitial cells for cytokine treatment to upregulate HLA class II molecules. This in turn may allow them to be accessed and sampled by the recipient's $\mathrm{T}$ cells, which will therefore become anergic. This may already be a contributory factor within patients with long-term valve performance. On the other hand, because endothelial cells normally provide an antithrombogenic surface, removing the endothelial layer may lead to a prothrombogenic state. An alternative solution may be to tissue engineer cardiac valves containing interstitial cells that have been altered to constitutively express HLA class II molecules in the absence of cytokine treatment. This approach would circumvent the upregulation of other proinflammatory molecules and soluble factors, which might cause dysfunction and deterioration of the implanted valve.

In conclusion, the present study shows that valve endothelial cells are relatively immunogenic in vitro, and therefore their immunogenicity may be extended to donordirected immune mechanisms in vivo. To verify and dissect the actual contribution of an ongoing immunologic response against the donor valves, prospective studies examining the frequency of donor-specific T-cell responses in patients implanted with either cryopreserved or high-dose antibiotic-treated valves may shed some light on how to dampen the alloresponse. Our results suggest that manipulation of cell-surface molecules on both the endothelial cells and the interstitial cells may offer an alternative strategy to divert the immune response away from the valve allografts.

\section{References}

1. Yacoub MH. Applications and limitations of histocompatibility in clinical cardiac valve allograft surgery. In: Yankah AC, Hetzer R, Miller DC, Ross DN, Somerville J, Yacoub MH, editors. Cardiac valve allografts, 1962-1987. New York: Springer-Verlag; 1987. p. 95-102.
2. O'Brien MF, Stafford EG, Gardner MA, Pohlner PG, Tesar PJ, Cochrane AD, et al. Allograft aortic valve replacement: long-term follow-up. Ann Thorac Surg. 1995;60:S65-70.

3. Suitters A, Rose ML, Higgins A, Yacoub MH. MHC antigen expression in sequential biopsies from cardiac transplant patients-correlation with rejection. Clin Exp Immunol. 1987;69:575-83Y.

4. Smith JD, Ogino H, Hunt D, Laylor RM, Rose ML, Yacoub MH. Humoral immune response to human aortic valve homografts. Ann Thorac Surg. 1995;60:S127-30.

5. Hogan P, Duplock L, Green M, Smith S, Gall KL, Frazer IH, et al. Human aortic valve allografts elicit a donor-specific immune response. J Thorac Cardiovasc Surg. 1996;112:1260-6.

6. Smith JD, Rose ML, Pomerance A, Burke M, Yacoub MH. Reduction of cellular rejection and increase in longer-term survival after heart transplantation after HLA-DR matching. Lancet. 1995;346:1318-22.

7. Clarke DR, Campbell DN, Hayward AR, Bishop DA. Degeneration of aortic valve allografts in young recipients. J Thorac Cardiovasc Surg. 1993;105:934-41.

8. Rajani B, Mee RB, Ratliff NB. Evidence for rejection of homograft cardiac valves in infants. J Thorac Cardiovasc Surg. 1998;115:111-7.

9. den Hamer I, Hepkema B, Prop J, Elzenga N, Ebels T. HLA antibodies specific for cryopreserved heart valve "homografts" in children. $J$ Thorac Cardiovasc Surg. 1997;113:417-9.

10. Hengstenberg C, Rose ML, Page C, Taylor PM, Yacoub MH. Immunocytochemical changes suggestive of damage to endothelial cells during rejection of human cardiac allografts. Transplantation. 1990;49:895-99.

11. Rose ML, Page C, Hengstenberg C, Yacoub MH. Identification of antigen presenting cells in normal and transplanted human heart: importance of endothelial cells. Hum Immunol. 1990;28:179-85.

12. Bishop DK, Shelby J, Eichwald EJ. Mobilization of T lymphocytes following cardiac transplantation: evidence that CD4positive cells are required for cytotoxic $\mathrm{T}$ lymphocyte activation, inflammatory endothelial development, graft infiltration, and acute allograft rejection. Transplantation. 1992;53:849-57.

13. Hoekstra F, Witvliet M, Knoop C, Akkersdijk G, Jutte N, Bogers A, et al. Donor-specific anti-human leukocyte antigen class I antibodies after implantation of cardiac valve allografts. J Heart Lung Transplant. 1997;16:570-2.

14. Johnson DL, Rose ML, Yacoub MH. Immunogenicity of human heart valve endothelial cells and fibroblasts. Transplant Proc. 1997;29:984-5.

15. Johnson DL, Sloan C, O'Halloran A, Yacoub MH. Effect of antibiotic pretreatment on immunogenicity of human heart valves and component cells. Ann Thorac Surg. 1998;66:S221-4.

16. Taylor PM, Allen SP, Yacoub MH. Phenotypic and functional characterization of interstitial cells from human heart valves, pericardium and skin. J Heart Valve Dis. 2000;9:150-8.

17. Page CS, Holloway N, Yacoub MH, Rose ML. Alloproliferative responses of purified CD4+ and CD8+ T cells to endothelial cells in the absence of contaminating accessory cells. Transplantation. 1994;57:1628-37.

18. Hargreaves R, Logiou V, Lechler R. The primary alloresponse of human CD4+ T cells is dependent on B7 (CD80), augmented by CD58, but relatively uninfluenced by CD54 expression. Int Immunol. 1995;7:1505-13.

19. Batten P, Yacoub MH, Rose ML. Effect of human cytokines (IFN $\gamma$, $\mathrm{TNF} \alpha, \mathrm{IL}-1 \beta, \mathrm{IL}-4)$ on porcine endothelial cells: induction of MHC and adhesion molecules and functional consequences of these changes. Immunology. 1996;87:127-33.

20. Batten P, McCormack AM, Page CS, Yacoub MH, Rose ML. Human T cell responses to human and porcine endothelial cells are highly sensitive to cyclosporin A and FK506 in vitro. Transplantation. 1999;68:1552-60.

21. McDouall RM, Page CS, Hafizi S, Yacoub MH, Rose ML. Alloproliferation of purified $\mathrm{CD} 4+\mathrm{T}$ cells to adult human heart endothelial cells, and study of second-signal requirements. Immunology. 1996;89:220-6.

22. Pober JS, Cotran RS. Immunologic interactions of T lymphocytes with vascular endothelium. Adv Immunol. 1991;50:261-302.

23. Mondino A, Jenkins MK. Surface proteins involved in T cell costimulation. J Leukoc Biol. 1994;55:805-15. 
24. Sperling AI, Bluestone JA. The complexities of T-cell co-stimulation: CD28 and beyond. Immunol Rev. 1996;153:155-82.

25. Hoekstra F, Knoop C, Aghai Z, Jutte N, Mochtar B, Bos E, et al. Stimulation of immune-competent cells in vitro by human cardiac valve-derived endothelial cells. Ann Thorac Surg. 1995;60:S131-3.

26. Simon A, Zavazava N, Sievers HH, Muller Ruchholtz W. In vitro cultivation and immunogenicity of human cardiac valve endothelium. $J$ Card Surg. 1993;8:656-5.

27. Ma W, Pober JS. Human endothelial cells effectively costimulate cytokine production by, but not differentiation of, naive CD4+ T cells. J Immunol. 1998;161:2158-67.
28. Maher SE, Karmann K, Min W, Hughes CC, Pober JS, Bothwell AL. Porcine endothelial CD86 is a major costimulator of xenogeneic human $\mathrm{T}$ cells: cloning, sequencing, and functional expression in human endothelial cells. J Immunol. 1996;157:3838-44.

29. Geppert TD, Lipsky PE. Antigen presentation by interferon-gammatreated endothelial cells and fibroblasts: differential ability to function as antigen-presenting cells despite comparable Ia expression. $J$ Immunol. 1985;135:3750-62.

30. Marelli-Berg FM, Lechler RI. Antigen presentation by parenchymal cells: A route to peripheral tolerance? Immunol Rev. 1999;172:297314 